\title{
The role of the university in attracting high tech entrepreneurship: A Silicon Valley tale
}

\author{
David Huffman, John M. Quigley \\ University of California, Berkeley, CA 94720-3880, USA (e-mail: quigley@econ.berkeley.edu)
}

\begin{abstract}
Among the many sorting functions provided by institutions of higher education, there is a geographic dimension. During the years spent as students and residents of local communities, students develop specific networks and contacts, and perhaps their tastes change as well. After graduation, these students may be more likely to reside in the locality or region in which they have been educated.

This paper presents evidence which suggests that the university is important in attracting human capital to the local area and in stimulating entrepreneurial talent in the region.

We also measure the strength of the impact of the university on geographical location in one specific instance. For post-graduate professional business and engineering students at Berkeley, we compare the spatial distribution of residences before attending the university and again after graduation.

The results are suggestive of the importance of academic institutions in the geographic pattern of agglomerations of footloose scientific firms, such as those in the Silicon Valley just south of San Francisco. The results also reinforce the self-interested reasons for government investment in high-quality educational institutions, as measured by the return on the augmented human capital stock in the region.
\end{abstract}

JEL classification: $\mathrm{H} 4$, I2, J4

\section{Introduction}

Institutions of higher education provide an important sorting function in the economy. They produce a wide variety of skills, and they sort individuals into occupations and professions. They also sort students by the quality of their

A previous version of this paper was presented at the Workshop on Entrepreneurship and Local Policy, Tinbergen Institute, Amsterdam, May 2000. Financial support for this research is provided by the Federal Emergency Management Agency and by the Berkeley Program on Housing and Urban Policy, University of California, Berkeley. 
human capital and by other measures of potential success in the labor market. Importantly, there is another, geographical, dimension to the sorting function provided by institutions of higher education. Students arrive at a university from other metropolitan areas, states, and often from foreign countries. During the years they spend as students and as residents of the local community, they develop specific networks and contacts; perhaps their tastes change as well. After graduation they may be more likely to reside in the locality, region, or state in which they have received their education.

This tendency may be more pronounced for graduate students than for undergraduates. Undergraduates have more recent experience living in the homes of their parents and are likely to return to these homes before setting out on their careers. The potential effect of educational institutions on the residential location of alumni is probably more pronounced for professional students than for those studying for academic degrees. In most respects, $\mathrm{PhD}$ 's face a thinner, and more geographically diffuse, labor market than do MBA's or engineers, for example.

This paper considers the impact of the university on the geographical concentration of human capital using the major educational institutions in the San Francisco Bay Area - Stanford University and the University of California, Berkeley - as examples. We discuss the formal and informal links between these universities and the scientific base in California, focusing on Silicon Valley, California's well-known agglomeration of high-tech firms. Silicon Valley provides a natural case study because of its importance in the California economy and because of the historically close ties between the Valley and local universities.

The paper also provides a more systematic analysis of the extent to which the University of California, Berkeley, acts as a magnet contributing to the region's human capital stock. It measures the strength of the impact of the university on geographical location, comparing the spatial distribution of UC Berkeley professional students at the time of their application for study to the distribution of the residences of the same students after graduation. In these comparisons, we use data for recent post-graduate professional students of Berkeley's Haas School of Business and its College of Engineering.

The comparisons indicate quite clearly that, after graduation, the individuals in these two groups are much more likely to reside closer to Berkeley. On average, their residential locations after graduation are about three hundred miles closer to the Berkeley campus.

The results of this descriptive analysis are suggestive of one role that major universities play in fostering regional development. The results suggest the importance of academic institutions in the development of agglomerations of footloose scientific firms such as Boston's Route 128 or Austin's Silicon Gulch. The results of this comparison also reinforce the self-interested reasons for government investment in high-quality public educational institutions. As a strategy for fostering economic development, public investment in education may greatly facilitate the import of human capital from the rest of the world. Educational investment may even be a "profitable" activity, measured narrowly on the basis of the returns to the augmented human capital stock which arises from government investment in educational institutions.

Section 2 presents a description of the formal and informal linkages between San Francisco Bay Area universities and Silicon Valley. Section 3 describes the data used for comparing the spatial distributions of UC Berkeley 
graduate students at the time of application and after-graduation. Section 4 offers a simple descriptive analysis measuring the relationship between attendance at the University of California, Berkeley, and geographical location. Section 5 concludes.

\section{Links between universities and California's scientific base}

In this section we present historical evidence on the links that arise between industry and universities which tend to strengthen the regional economy. These links help to channel human capital to local firms and stimulate local entrepreneurial talent. We begin with a brief description of the close ties between Silicon Valley and Stanford University, dating back to the early 1950's, and continue with a catalog of some of the current linkages between Silicon Valley and both Stanford and the University of California, Berkeley.

It is widely believed that Silicon Valley's beginning was the brainchild, more-or-less, of Frederick Terman, the Dean of the Stanford University School of Engineering in the 1950's. As recounted in the professional press (Aley 1997), Terman had a specific vision. He was intensely frustrated with the tendency of talented Stanford graduates to leave the West Coast for jobs and careers in the East, so he decided to "do something" about it. Terman conceived of a center of high technology around Stanford that would help California and the local area to retain some share of this pool of locallyproduced talent.

Terman set out to develop collaborative ties between Stanford and local industry that would help the regional high-tech economy prosper. Terman encouraged faculty and students to schedule study trips to nearby firms to learn of opportunities for research and local employment. He became a champion for internships and jobs for Stanford students at local firms. Terman spoke regularly at industry meetings, exhorting the local business community to learn how Stanford research might help their companies (Saxenian 1996). Terman also arranged for local start-up firms to get access to Stanford research before it was published, and he invited engineers from local firms to participate in the Honors Cooperative Program, a part-time professional degree program (Feder 1999).

Terman was instrumental in the development of a key institutional innovation, the Stanford Industrial Park. This was one of the world's first planned industrial parks, located on 220 acres of university-owned land within walking distance of campus. Terman hoped to capitalize on Stanford's land endowment by offering leases to specific companies that might also benefit the university. Over the years, these benefits included ties to Stanford faculty, as consultants, and to graduates, as employees. The park's first tenant, Varian Associates, located its operations in the park in the late 1940's so as to "bring the company closer to old friends, ease ongoing collaborations, and improve access to graduate students in physics and electrical engineering." (Saxenian 1996). Other firms soon followed, including General Electric, Eastman Kodak, Admiral Corporation, Hewlett-Packard, and Watkins-Johnson. By 1965, the Stanford Industrial Park had 42 tenant companies which provided employment for approximately 12,000 people (Feder 1999). 
As the cold war stimulated military spending in the 1950's, Terman sought to attract national aerospace and electronic firms to the area around Stanford. In 1956, at Terman's urging, Lockheed Aerospace Company established a research laboratory in the new industrial park. One year later, Lockheed moved its Missile and Space Division from Burbank to Sunnyvale (Norr 1999). As often happened with new neighbors, Stanford encouraged faculty in the advising and training of employees. In return, Lockheed played a major role in building the internal reputation of Stanford's Aeronautical Engineering Department (Saxenian 1996).

The scientific base around Stanford continued to attract established firms during the 1950's and 1960's, but the relatively new semiconductor sector, born in 1951, became the largest and fastest growing. The Santa Clara Valley became known as Silicon Valley, named for the material used in making semiconductors. By 1975, Silicon Valley's high-tech companies employed over 100,000 workers, and the Valley had become one of the nation's leading centers of electronics innovation and production (Saxenian 1996).

The University of California, Berkeley, located thirty miles north of Stanford, became an important source of research and talent for Silicon Valley firms during the 1960's and 1970's. Although small in the 1950's, Berkeley's engineering program grew rapidly, training almost as many engineers as Stanford by the mid-1970's. Berkeley had become an important independent center of research on semiconductors and computers by 1970.

In her authoritative book on Silicon Valley, Annalee Saxenian emphasizes the historical importance of the combined contribution of the universities at Stanford and Berkeley: "The presence of two world-class scientific and research universities that were actively involved in Silicon Valley industry created a scientific milieu unparalleled elsewhere in the nation." (Saxenian 1996, p. 42) The symbiosis between Silicon Valley and local universities has continued to generate economic benefits for the state and the nation. For example, by 1996, according to a Stanford Business School study, as many as 100 "Stanford start-ups" in Silicon Valley have generated more than $\$ 65$ billion in economic output (Feder 1999).

Stanford, Berkeley, and other California universities continue to maintain a variety of links with firms located in Silicon Valley. Some of these links are formal and institutionalized, such as annual recruitment programs with on-campus presentations and job interviews. Many of these links are quite informal, for instance those that grow out of connections made at industryuniversity social events. In what follows we describe several different types of links and illustrate them with several concrete examples. The examples come from Berkeley's Haas School of Business and its College of Engineering, as well as the Stanford Business and Engineering Schools.

On-campus recruiting by firms is perhaps the most obvious formal channel affecting the flow of graduates from universities to jobs in the local economy. Representatives from firms visit campuses to interview job applicants and advertise to students who may apply for employment in the future. For example, the Electrical Engineering and Computer Science (EECS) Department in the Berkeley College of Engineering sponsors an Industrial Liaison Program (ILP), which invites companies to the Berkeley campus for a variety of recruiting events. Interested firms join by paying $\$ 7,500$; in return the ILP arranges and advertises on-campus information sessions and interviews. Participating firms are invited to an annual conference highlighting research 
accomplishments of faculty and students; firm representatives can also attend more-informal networking events.

Although Silicon Valley firms recruit on university campuses throughout the country, physical proximity makes it easier for California universities to draw a wide variety of firms to campus and to stay abreast of the latest developments in the high-tech labor market. For instance, a staff member of Berkeley's Haas School of Business Recruiting Office spends one day a week in Silicon Valley, marketing the business school directly to selected firms and collecting information on Silicon Valley hiring trends.

The proximity of Stanford to Silicon Valley facilitates a remarkable variety of on-campus recruiting activities. For example, Silicon Valley firms have been known to "stake out" certain computer science courses offered at nearby Stanford, targeting hiring efforts at former section leaders for these courses (so as to exploit these section leaders' connections with other computer science students). At times, companies exploiting these linkages have dispatched section-leader hires to campus to deliver recruiting pitches during pre-class announcements. This is no longer permitted, but still happens occasionally, according to Stanford students recently quoted in the business press (Aley 1997).

"Networking events" are another institutionalized link between firms and universities. Universities and firms arrange "networking receptions" where students and representatives of local firms can establish contacts that may lead to future employment relationships. As noted above, the ILP of Berkeley's EECS department sponsors this sort of event as part of an annual conference. Poster sessions, featuring current student research, facilitate informal contact with representatives of firms. Berkeley's Haas School of Business sponsored a networking event in January 2000 jointly with the University of Chicago. This illustrates nicely the advantages of proximity to Silicon Valley. Silicon Valley firms and students of both universities were invited to a reception; the University of Chicago participated in the event because distances make smaller Silicon Valley firms reluctant to visit the Chicago campus. In fact, it is reported that the idea arose largely because many University of Chicago students routinely visit Silicon Valley during their January vacation to prospect for employment.

Universities often have "networking events" that specifically target their own alumni. Alumni representatives of a firm are more likely to hire someone from their alma mater, all else being equal. The Haas School's recruitment office organizes a variety of events with alumni employed in Silicon Valley, and the Haas student technology club organizes its own networking event, "High-Tech Night," in the Spring with Silicon Valley alumni. Again, proximity to Silicon Valley makes these activities feasible.

Internships are a time-honored way of establishing connections between students and firms that may lead to employment after graduation. There are many reasons why internships can lead to future employment. Students learn skills (some of them firm-specific) that make them more attractive hires in the future; students have a chance to make contacts within firms, and firms have the opportunity to evaluate and ultimately to "court" promising interns.

Silicon Valley firms visit the Haas School regularly to interview students for internships. The Haas School reports that twenty percent of students with summer internships ultimately accept employment with the same firm after 
graduation (Placement Report 1999). The Lester Center for Entrepreneurship and Innovation at the Haas School provides another avenue for finding internships - the Center matches students with internships in local startup firms (CalBusiness Spring 1997). Students in the College of Engineering also use the internship route to employment. Some, mostly undergraduates, take advantage of a summer internship program.

Some firms provide scholarships to especially promising students in anticipation of employment after graduation. Usually these scholarships do not involve an obligation to work for the firm, but they may require the student to undertake a summer internship. As discussed above, the internship component is an effective recruiting tool. For example, Sun Microsystems offers scholarships linked to (paid) summer internships to several students every year in both Berkeley's Business School and its College of Engineering.

Universities also provide resources that help students become selfemployed. In addition to classes on entrepreneurship, as in the Haas School, universities support students starting their own businesses in a variety of other ways. Most important of these for the eventual success of student businesses may be the universities' contacts with established local firms. For example, a group of Haas students, aware of the value of contacts with fellow entrepreneurs in establishing a new business, have formed an unusual alumni group. All members of the Haas Founders' Forum are entrepreneurs, or stakeholders in startup firms, or are employed providing services for entrepreneurs. Forum members communicate by email, through a common web site, and through monthly social functions (CalBusiness Fall 1999).

Business "incubators" run by universities support students starting their own ventures. These incubators provide office space, equipment, and advice from professors and successful entrepreneurs. Sometimes these fledgling businesses attract funding and become profitable local firms.

Berkeley has two incubators: Incubator Inc., devoted entirely to internetrelated businesses; and the Berkeley Business Incubator, which accepts different types of ventures (UC Berkeley News Release April 29, 1997). Both of the organizations provide students with access to a group of important local firms. Francois Jeanneau, MBA '97 and founder of a successful online videoshopping business (Video@YourFingertips), confirms the importance of these contacts: "The network of people the Berkeley Business Incubator connects me with is very helpful, very important." (CalBusiness Fall 1997)

One example of success from the Berkeley Business Incubator is zipRealty.com, a firm facilitating the purchase and sale of real estate using online brokers. Founded by two MBAs from the class of 1999 and headquartered in Berkeley, zipRealty.com has grown to 29 employees and has attracted \$1.7 million in funding, \$1.2 million of which comes from Silicon Valley's Vanguard Venture Partners (CalBusiness Spring 1999, Fall 1999).

Business plan competitions also encourage entrepreneurial activity, and can link entrepreneurs to sources of funding. In these competitions, groups of students present business plans to a panel of judges composed of representatives of prominent venture capital firms and business consultants. The more successful plans may ultimately receive funding from some of the firms judging the contest. Stanford and Berkeley both host business plan competitions relying upon panels of local judges.

In a recent Berkeley Business Plan Competition (1999), over 70 entrepreneurs entered, and 44 business plans were produced. Most of the plans 
involved collaboration among students from different departments in the university; the vast majority were technology-related. Of the eight finalists, two technology-related plans received substantial funding and are well on their way to becoming successful startups (CalBusiness Spring 1999).

Many sources suggest that less-formal links than those described above play an important a role in the interaction between Silicon Valley and California universities. Fortune magazine (July 1997) quotes Berkeley's AnnaLee Saxenian: "Much of what goes on between university and industry has to do with people starting out as faculty or students. They keep in touch. People go back and forth from academia to industry. Much of this is informal." Certainly, research, funding, and educational relationships between firms and universities lead to contacts that enhance employment and entrepreneurial opportunity, even though these are not recruiting or networking channels in any formal sense.

Funding and research relationships between businesses and universities can lead indirectly to the employment of graduates and alumni. When a firm provides funding for new facilities, i.e., a building or laboratory, the firm may garner more applicants simply from its increased visibility among students. Funding for facilities and equipment also fosters industry-related skills for the donor, increasing the pool of qualified applicants.

Stanford's profusion of donated facilities and endowed faculty positions testifies to the keen interest of Silicon Valley firms in establishing a presence on campus. For example, 20 of Stanford's 41 engineering chairs have been endowed by high-tech companies, Silicon Valley executives, and venture capitalists. In 1992, buildings were named for donors Bill Gates of Microsoft and Paul Allen of Netscape. Chih-Yuan Yang and David Filo of Yahoo have endowed a chair for research focusing on the internet and entrepreneurship. A recent gift from Lucent Technologies has established a wing of Bell Laboratories at the Stanford Research Park, endowed a professorship, and established two graduate fellowships (Healy 1998).

An important informal source of employment seems to be the contacts between professors and industry that result from research, funding, and alumni relationships. For instance, firms typically ask faculty for assessments of promising students. "Affiliates" of the ILP in the College of Engineering (who pay $\$ 125,000$ annually) are invited to place a visiting researcher on the Berkeley campus. Presumably this makes it easier to forge useful informal connections. Affiliates of the ILP include major Silicon Valley firms such as Intel and Hewlett Packard.

Local firms become part of the curriculum and educational experience at universities, facilitating the development of industry-related skills and providing opportunities for students to make valuable contacts. For example, Haas student Steve Sellers, who had recently founded the startup firm Archetype Interactive Corp., got to know his instructor in "New Venture Finance." The instructor is a member of a prominent law firm. The firm ultimately became corporate counsel for Archetype, providing the kind of support that is crucial for the success of a startup. As suggested by another Haas netrepreneur: "A connection like that can catapult a new venture over nine out of ten competitors" (CalBusiness Spring 1997). Recently, Stanford University's new Center for Electronic Business and Commerce has developed a class that allows students to work directly with Silicon Valley e-commerce companies (Kirby 1999). 


\section{A quantitative assessment}

As the foregoing discussion suggests, linkages between Bay Area universities and Bay Area employers are strong. Graduate professional students attracted to California for educational reasons alone may find themselves much more likely to settle in California and to choose employment within the region. This section provides a quantitative assessment of this association using student records from the University of California.

Each applicant to the University of California, Berkeley indicates a home of record and a five-digit postal code (zip code) on his or her original application for study. For all the reasons suggested above, Berkeley's graduate and professional schools strive to maintain the current addresses of all alumni.

We surveyed the records of professional masters students at Berkeley's Haas School of Business and its College of Engineering, extracting the alumni records of recent graduates. We gathered the alumni records of masters graduates of the business school matriculating between 1993 and 1998 (941 MBA and 7 MS graduates) and the alumni records of engineering students graduating between 1994 and 1997 (836 MS and 60 ME graduates).

We matched these alumni records to the graduate school applications which had been submitted by these individuals several years earlier. From the five-digit postal codes at application and after graduation, we computed the airline distance of each individual to Berkeley before and after matriculation. ${ }^{1}$

Table 1 reports summary information on the sample so selected. A total of 3,213 records were surveyed; the overwhelming majority were MBA graduates from the Business School and MS graduates from the College of Engineering. Of the records selected, a total of 128 admitted for study in business resided abroad at the time of application, and 164 successful engineering applicants were living abroad at the time of application. Of the graduates surveyed, a

Table 1. Average distance of residence from Berkeley for professional school applicants and graduates

\begin{tabular}{|c|c|c|c|c|}
\hline & \multicolumn{2}{|c|}{$\begin{array}{l}\text { Haas School of } \\
\text { Business } \\
\text { 1994-1997 }\end{array}$} & \multicolumn{2}{|c|}{$\begin{array}{l}\text { College of } \\
\text { Engineering } \\
1994-1997\end{array}$} \\
\hline & \multicolumn{2}{|c|}{ Program } & \multicolumn{2}{|c|}{ Program } \\
\hline A. Sample sizes & MBA & MS & MS & ME \\
\hline Number of records surveyed & 1839 & 19 & 1263 & 92 \\
\hline Number of applicants from abroad & 126 & 2 & 145 & 19 \\
\hline Number of alumni living abroad & 294 & 2 & 54 & 7 \\
\hline Number of domestic applicants and graduates & 941 & 7 & 839 & 60 \\
\hline \multicolumn{5}{|l|}{ B. Distance from Berkeley* } \\
\hline \multirow[t]{2}{*}{ Average distance for domestic applicants (miles) } & 590.31 & 1182.68 & 881.14 & 914.43 \\
\hline & $(943.70)$ & $(1066.40)$ & $(987.30)$ & $(931.80)$ \\
\hline \multirow[t]{2}{*}{ Average distance for domestic graduates (miles) } & 300.96 & 543.99 & 486.69 & 642.26 \\
\hline & $(695.20)$ & $(967.70)$ & $(825.60)$ & 931.70 \\
\hline
\end{tabular}

* Standard deviations in parentheses.

1 Distances were available for all individuals whose graduate school application and alumni record listed U.S. postal codes. The ArcView program was used for the calculations. 
Table 2. Distribution of applicant and alumni residence in California, US outside California, and abroad (percent)

\begin{tabular}{lccc}
\hline Alumni residence & \multicolumn{3}{c}{ Applicant residence } \\
\cline { 2 - 4 } & California & $\begin{array}{l}\text { US, outside } \\
\text { California }\end{array}$ & Abroad \\
\hline A. Haas School of Business & & & \\
$\quad$ California & $47.3 \%$ & $13.4 \%$ & $7.6 \%$ \\
US, outside California & 5.7 & 5.6 & 14.9 \\
$\quad$ Abroad & 2.4 & 1.0 & 9.2 \\
B. College of Engineering & 52.0 & 11.8 & 1.2 \\
$\quad$ California & 11.7 & 8.5 & 4.9 \\
$\quad$ US, outside California & 0.4 & 0.5 & \\
Abroad & & & \\
\hline
\end{tabular}

total of 296 graduates of the Haas School from 1993-1998 were residing abroad in 1998, and 61 graduates of the Engineering School from 1994-1997 were residing abroad.

A total of 948 business graduates and 899 engineering graduates applied from residences in the US and now, after graduation, live in the US. For these individuals, it was possible to compute the distances of their residences from Berkeley. As Table 1 indicates, the average distance from the Berkeley campus (zip code 94720) of MBA applicants is 590 miles, and the average distance from the Berkeley campus is 881 miles for MS (engineering) applicants. These averages conceal a great deal of variation.

After graduation, these average distances were reduced to 301 miles for MBAs and 487 miles for MS engineers.

Table 2 summarizes the pre- and post-graduate school residential pattern for these students. Among business school students, $47 \%$ lived in California before entering Berkeley's masters program and continued to live in California after graduation; $5.6 \%$ originally lived in other states in the U.S. and also lived in other states after graduation. Almost $15 \%$ resided outside the U.S. before attending business school and now reside outside the U.S. The offdiagonal elements indicate that more than $13 \%$ of applicants resided outside California before attending business school while $5.7 \%$ of applicants resided in California before attending business school but now reside outside California. The pattern of the net in-migration of Berkeley students to California is similar, but less pronounced, for engineering students.

\section{Some simple descriptive analysis}

As indicated in Table 1, the average distance at which business school alumni live from the Berkeley campus declined by $49 \%$ after graduation and the average distance for engineering students declined by $44 \%$. These residential relocations are, of course, not uniform. Students applying from more distant locations do tend to live farther away from Berkeley after graduation. Table 3 presents a simple regression summary of the link between distance from Berkeley before and after attendance at one of these professional schools. For 
Table 3. Distance of residence after graduation as a function of distance at application $(t$ ratios in parentheses)

\begin{tabular}{lcc}
\hline & $\begin{array}{c}\text { Business } \\
\text { students }\end{array}$ & $\begin{array}{l}\text { Engineering } \\
\text { students }\end{array}$ \\
\hline Distance at application & 0.185 & 0.320 \\
Constant & $(7.99)$ & $(12.22)$ \\
& 191.827 & 213.912 \\
$(6.18)$ \\
$R$-squared & $(7.42)$ & 0.38 \\
Sample size & 0.25 & 899 \\
\hline
\end{tabular}

Table 4. Estimates of probability distribution of residential locations as a function of distance ( $t$-ratios in parentheses)

\begin{tabular}{ccccc}
\hline & \multicolumn{3}{c}{$P_{j}=\beta * \exp ^{-\beta t_{j}}$} \\
\cline { 2 - 5 } & \multicolumn{3}{c}{ Business students } & \multicolumn{2}{c}{ Engineering students } \\
\hline \multirow{3}{*}{$\beta\left(\times 10^{2}\right)$} & At application & After graduation & At application & After graduation \\
& 1.006 & 1.612 & 0.461 & 2.171 \\
& $(31.33)$ & $(36.36)$ & $(31.77)$ & $(31.83)$ \\
\hline
\end{tabular}

business school alumni, a 100 mile increase in distance at application is associated with a 19 mile increase in distance after graduation; for engineering alumni a similar 100 mile increase in distance at application is associated with a 32 mile increase in distance after graduation. These effects are statistically significant, but prior distance from Berkeley explains only a small fraction of post-graduation distance, between one quarter and three eighths.

Interaction over space is often modeled using the gravity representation, in which the probability of interaction is assumed to decline at some constant relative rate (See Isard 1960, for the definitive treatment). The general statement of this model is of the form:

$$
P_{j}=\alpha e^{\left(-\beta t_{j}\right)}
$$

Where $P_{j}$ is the probability of interaction at location $j$ measured from the center and $t_{j}$ is the distance between the center and location $j$. We apply this model to the residences of Berkeley business and engineering students. In this analysis, the dependent variable $P_{j}$ is computed as the fraction of applicants and graduates at various distances, $t_{j}$, from Berkeley. Table 4 reports statistical estimates of Eq. (1). These results were obtained by imposing the restriction that the probability cumulates to one. ${ }^{2}$ The coefficient reported is the gradient of population decline per mile of distance from the Berkeley campus. The coefficients are highly significant.

Figures $1 \mathrm{a}$ and $1 \mathrm{~b}$ graph these proportions as functions of distance using

${ }^{2}$ From Eq. (2), when $j=\infty, C_{j}=1$ if $\alpha=\beta$. 

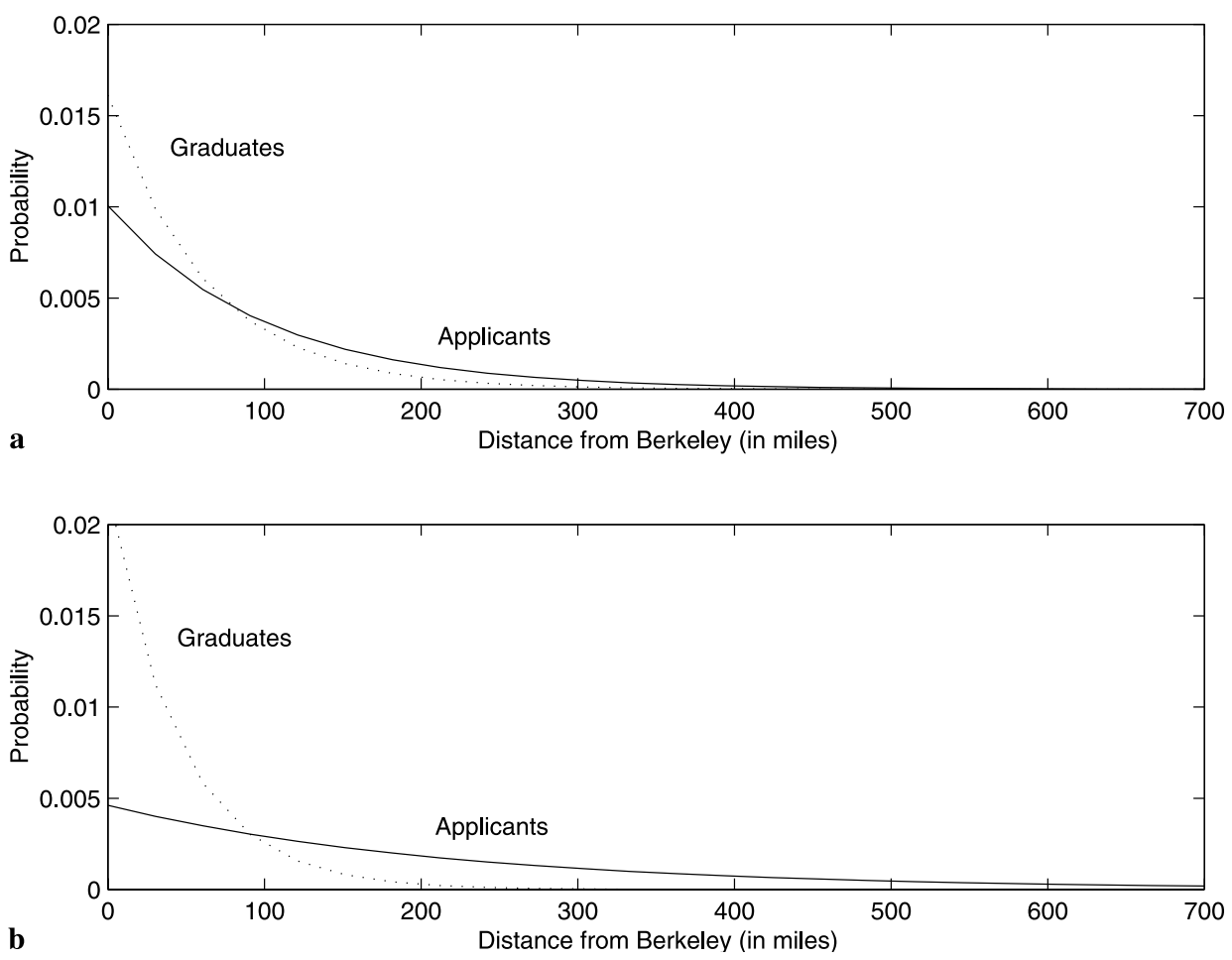

Fig. 1a. Density of applicants and graduates as a function of distance, Haas School of Business; b Density of applicants and graduates as a function of distance, College of Engineering

the estimated gravity model. As is apparent, these functions are much more heavily concentrated at distances closer to the Berkeley campus. For both schools, graduates are more concentrated around Berkeley than applicants. A comparison of the functions for the business and engineering students suggests that engineering applicants are more dispersed than business applicants, but that engineering graduates are more concentrated than business graduates.

The effect of distance may be easier to describe with reference to the cumulative distribution of applicants and graduates. Figures $2 \mathrm{a}$ and $2 \mathrm{~b}$ plot the cumulative fractions of successful applicants and graduates as functions of distance from Berkeley. These cumulative fractions $C_{j}$ are merely

$$
C_{j}=\beta \int_{0}^{t_{j}} e^{\left(-\beta d_{t}\right)} d t_{j}
$$

The graphs indicate that the cumulative fraction of business applicants residing within 300 miles of Berkeley is about 95\%; the cumulative fraction of business graduates living within 300 miles is about $99 \%$. A similar comparison for engineering students indicates that the cumulative fraction within 300 miles increases from about $75 \%$ to approximately $99 \%$ between time of application and graduation. 

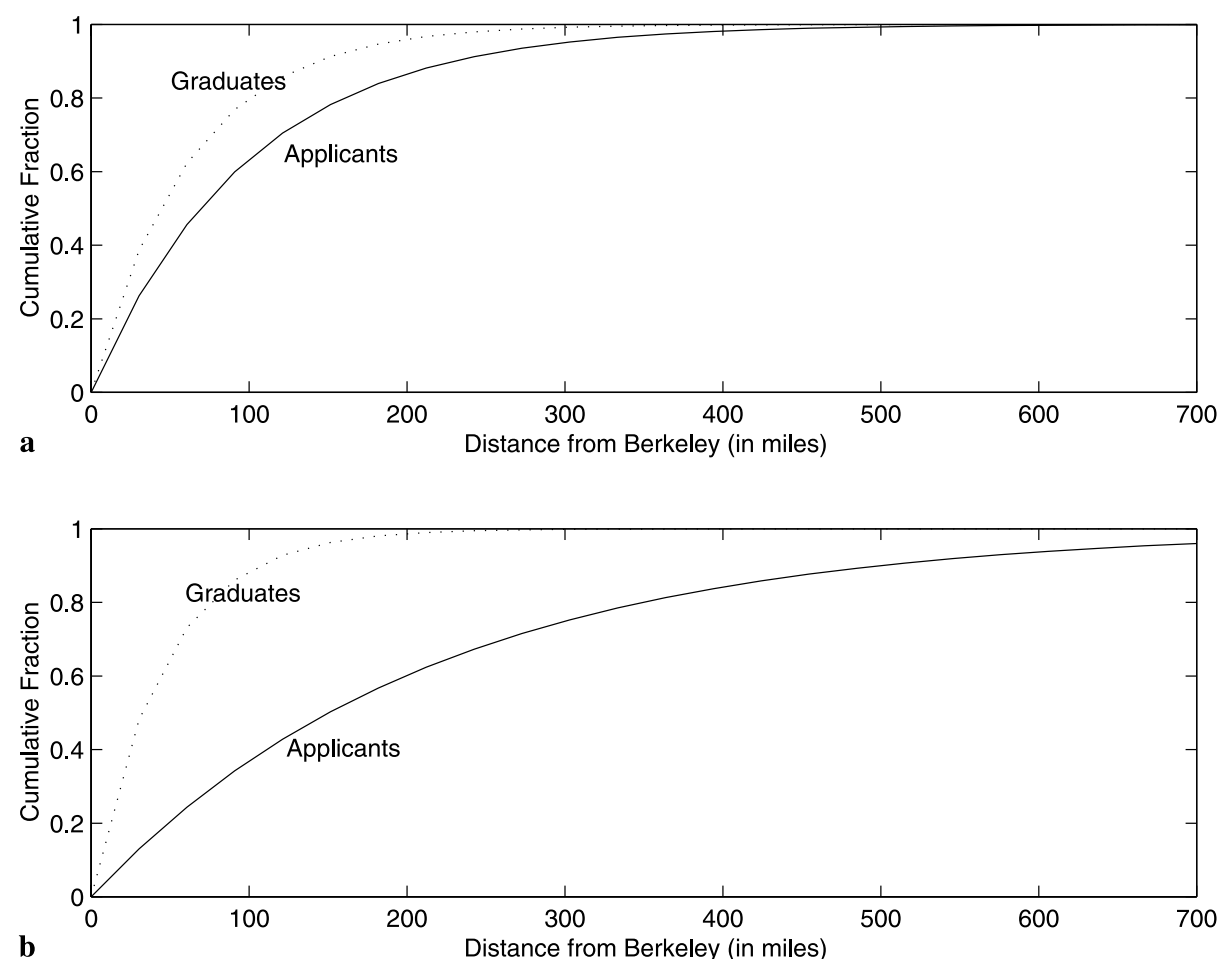

Fig. 2a. Cumulative fraction of applicants and graduates as a function of distance, Haas School of Business; b Cumulative fraction of applicants and graduates as a function of distance, College of Engineering

Some perspective on these findings is offered by Fig. 5. The figure indicates distance in hundred mile increments from Berkeley. A radius of three hundred miles extends south to San Diego and north to Salem, Oregon. It also extends east as far as Las Vegas, Nevada. The overwhelming majority of Berkeley business and engineering graduates live in this 300 mile band.

There is some indication that these relationships have changed over time. Table 5 reports the regression results for earlier and later graduating classes. Figures $3 \mathrm{a}, \mathrm{b}$ and $4 \mathrm{a}, \mathrm{b}$ graph these proportions. Both schools show a trend towards greater concentration after graduation in the later years.

Table 6 presents the results of estimating a standard logit model

$$
\operatorname{Prob}\left(P_{i}=1\right)=f\left(x_{i} \beta_{0}\right)
$$

where the dependent variable, $\operatorname{Prob}\left(P_{i}=1\right)$, is the probability of California residence after graduation, $x_{i}$ is a vector of explanatory variables, and $\beta_{0}$ is a vector of parameters. The function $f(\cdot)$ is the logit distribution function. Equations (2) and (4) include an indicator for foreign applicants in the basic set of explanatory variables. The explanatory variables include California residence at time of application, graduating-class year, and distance from Berkeley at time of application. Adding foreign students necessitates the dis- 
Table 5. Estimates of probability distribution of residential locations as a function of distance $(t$-ratios in parentheses)

\begin{tabular}{|c|c|c|c|}
\hline \multicolumn{4}{|c|}{$P_{j}=\beta * \exp ^{-\beta t_{j}}$} \\
\hline \multicolumn{2}{|c|}{ Earlier classes* } & \multicolumn{2}{|c|}{ Later classes* } \\
\hline At application & After graduation & At application & After graduation \\
\hline
\end{tabular}

A. Business students $\beta\left(\times 10^{2}\right)$

0.978

(23.86)

B. Engineering students $\begin{array}{lr}\beta\left(\times 10^{2}\right) & 0.468 \\ & (23.94)\end{array}$
1.500

(26.50)

1.934

(22.55)
1.052

(20.32)

0.452

(20.88)
1.743

(22.48)

* For business students, earlier classes are those graduating in 1993-1995, and later classes are those graduating in 1996-1998. For engineering students, earlier classes are those graduating in 1994-1995, and later classes are those graduating in 1996-1997.

tance variable (since distances from foreign locations to Berkeley are not available in these data).

Table 6 indicates that for business students, California residence at the time of application is associated with a statistically significant increase in the probability of living in California after graduation. Classes 1996-1998 exhibit a significantly higher probability of living in California after graduation, relative to the class of 1993. Distance at the time of application does not have a significant impact on the probability that business students live in California after graduation. Foreign applicants to the Business School are significantly less likely to live in California after graduation than are domestic applicants.

\section{Conclusion}

The strong association between matriculation at a professional school in California and ultimate residence in the state may over estimate the role of educational institutions in affecting behavior. To the extent that employment opportunities in California are superior, graduates of all elite business and engineering schools may be more inclined to migrate to the state. Nevertheless, these simple statistical results support the claim that the university, at least the Berkeley campus of the University of California, exerts some concentrating effect on the spatial distribution of graduates relative to applicants. The average distance from Berkeley and the proportion of students residing further than any given distance decline after graduation for alumni of both the Business and Engineering Schools. This concentrating effect also appears to be increasing over time. Comparison of the two schools indicates that the increased concentration is more dramatic for engineers, in the sense that the increase in cumulative percent living within a given distance of Berkeley is larger.

The percent of business school graduates living in California is consistently higher than the percent of business applicants living in California. The percent 

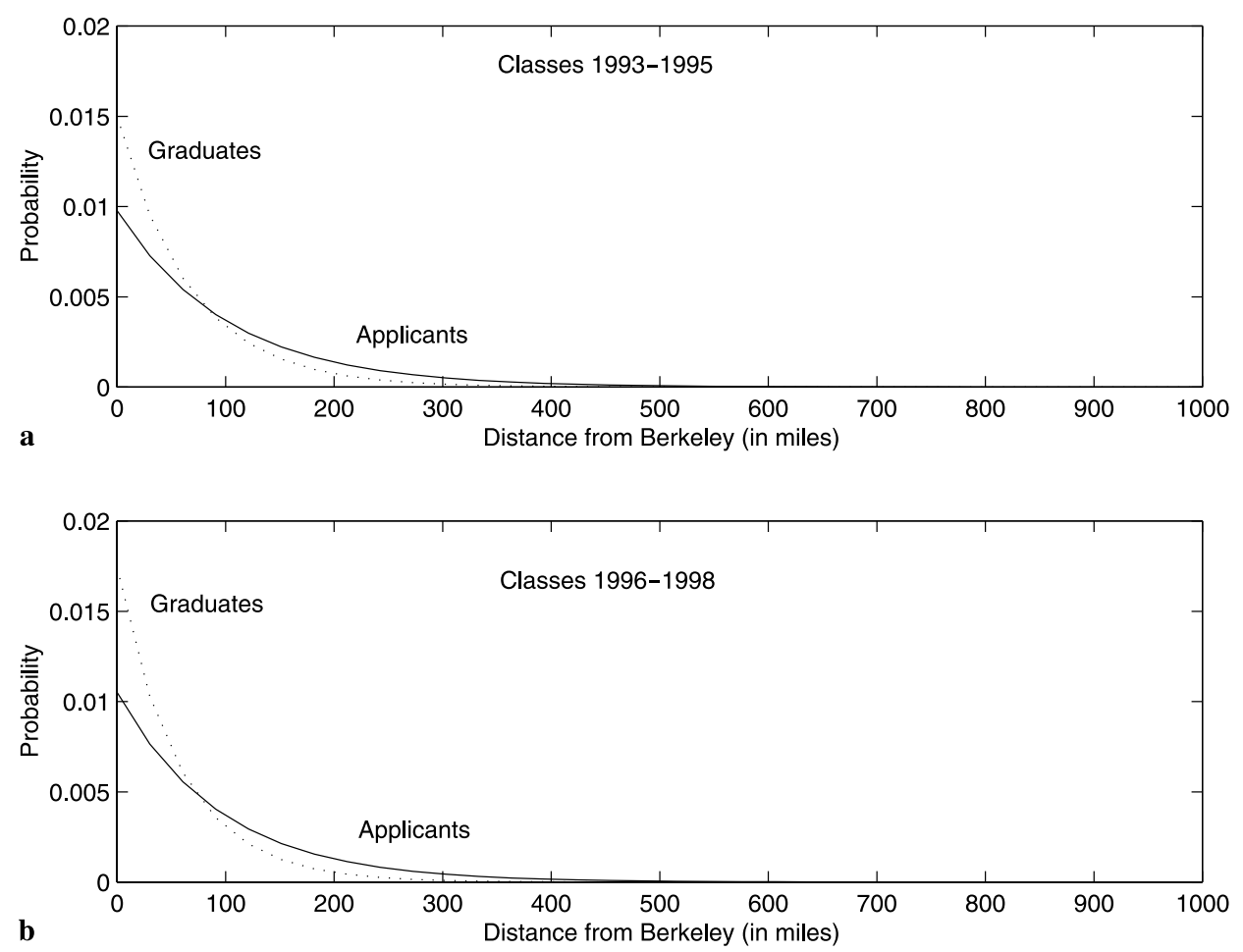

Fig. 3a. Density of applicants and graduates as a function of distance, Haas School of Business; b Density of applicants and graduates as a function of distance, Haas School of Business

of engineering graduates living in California also increases, relative to applicants, for the early graduating classes. For the last two classes, however, the percent living in California was higher among applicants. ${ }^{3}$

The results are suggestive of the benefits to the state which accrue because the university attracts students from out of state who then reside in California after graduation. These alumni who would otherwise live elsewhere have high incomes. Table 7 reports one such comparison, based on national data from the Current Population Survey (CPS). As the table suggests, the earnings of U.S. workers aged 25-34 years with masters degrees averaged about $\$ 46,000$ in 1998 , increasing to almost $\$ 68,000$ for ages 55-64. At a five percent real interest rate, the present value of the lifetime earnings of a 25 year old with a masters degree is about $\$ 994,000$. Thus, each out-of-state masters degree applicant with this potential earnings profile would increase state domestic product by almost a million dollars. The multiplier effects upon the regional

\footnotetext{
${ }^{3}$ In other statistical results, not reported, we find that conditioning on out-of-state application does not change the results for business students, but does yield a contrast between out-of-state engineering applicants and engineering students as a whole. Specifically, the probability of California residence after graduation does not increase with distance at time of application for outof-state engineering applicants. Also, graduating class does not have a significant effect for outof-state applicants.
} 

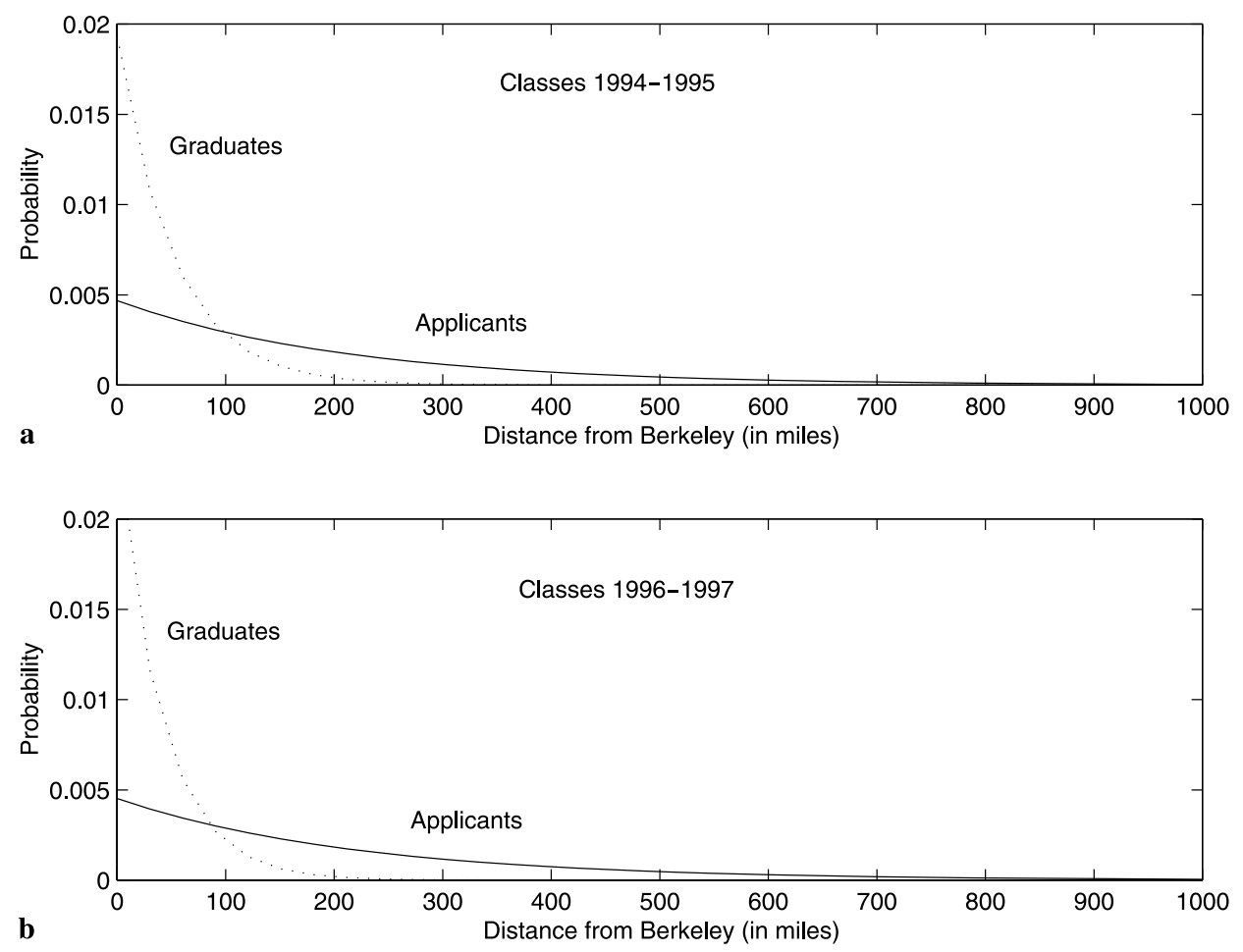

Fig. 4a. Density of applicants and graduates as a function of distance, College of Engineering; b Density of applicants and graduates as a function of distance, College of Engineering

economy might increase the impact of this induced immigration to California to $\$ 1.5 \mathrm{M}$ or more in state output.

Of real importance to the state government, of course, are the implications of this increase in output for state tax revenues. At a tax rate of ten percent, the present value of the tax liabilities of the average masters graduate are on the order of $\$ 94,000$. If the indirect stimulus to the California economy is considered, the effect upon tax revenues may be $\$ 150,000$ or more in present value terms.

Of course, the average salaries of Berkeley masters graduates greatly exceed the average incomes reported in the CPS. For example, the average starting salary plus bonus of 1999 MBA graduates of Berkeley's Haas School of Business is \$105,000 (Placement Report 1999).

Using the same assumptions embodied in Table 7, this starting salary suggests that the present value of state product directly attributable to a masters graduate is more than $\$ 2.25 \mathrm{M}$. Including indirect effects of this stimulus might lead to a total increase in state output of $\$ 3.75 \mathrm{M}$ or more, in present value terms.

In terms of tax revenue to the state of California the effect of each out-ofstate applicant who is induced to reside in California after graduation is about $\$ 225,000$ in direct benefits and about $\$ 375,000$ in total benefits, in present value terms. 


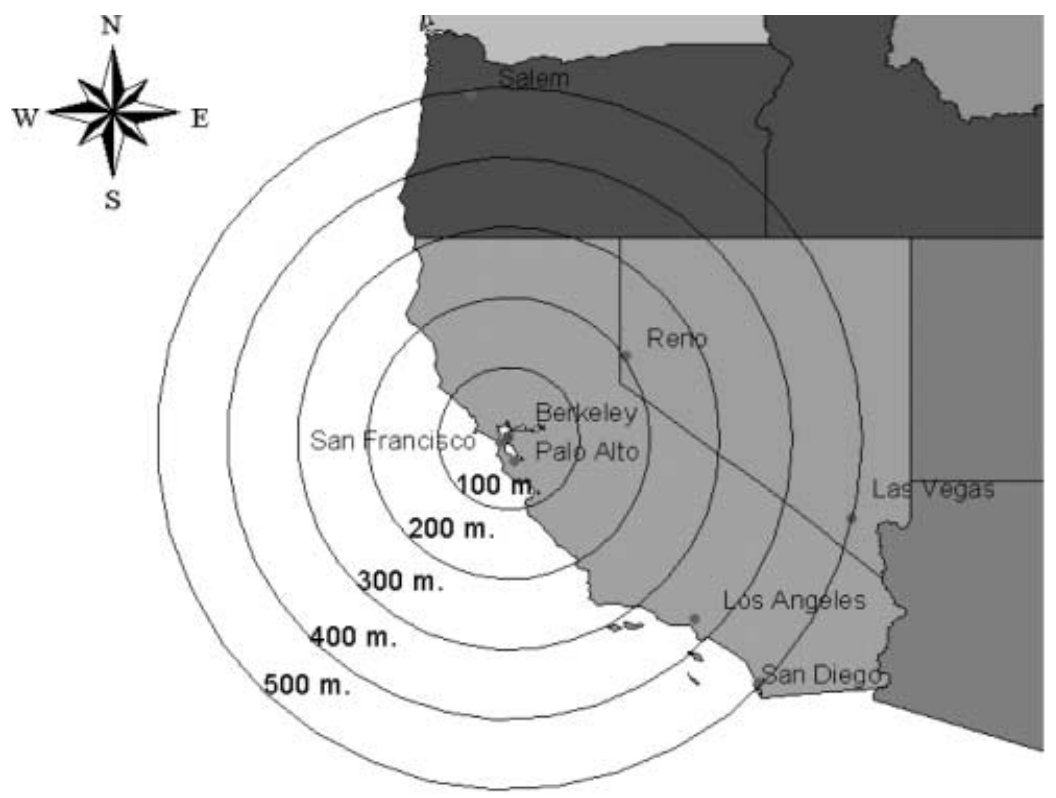

400

0

400

800 Miles

Fig. 5. Distances from Berkeley, California

Table 6. Probability of California residence after graduation as a function of explanatory variables ( $t$ ratios in parentheses)

\begin{tabular}{lccccc}
\hline \multirow{2}{*}{ Dependent variable: } & \multicolumn{3}{c}{ Probability of California residence after graduation } \\
\cline { 2 - 3 } & \multicolumn{2}{c}{ Haas School of Business } & & \multicolumn{2}{c}{ College of Engineering } \\
\cline { 2 - 3 } \cline { 5 - 6 } Explanatory variables & $(1)$ & $(2)$ & & $(3)$ & $(4)$ \\
\hline \multirow{2}{*}{ Intercept } & -2.188 & -1.503 & & -3.042 & -1.342 \\
& $(-5.12)^{* *}$ & $(-4.92)^{* *}$ & & $(-10.47)^{* *}$ & $(-8.49)^{* *}$ \\
Lived in CA at application & 0.585 & 0.558 & & -0.522 & 0.598 \\
& $(2.525)^{*}$ & $(6.53)^{* *}$ & & $(-3.372)^{* *}$ & $(7.082)^{* *}$ \\
Class 1994 & 0.073 & 0.120 & & - & - \\
& $(0.608)$ & $(1.141)$ & & - & - \\
Class 1995 & 0.197 & 0.272 & & 0.133 & 0.097 \\
& $(1.406)$ & $(2.278)^{*}$ & & $(1.25)$ & $(1.055)$ \\
Class 1996 & 0.488 & 0.386 & & 0.266 & 0.246 \\
& $(3.089)^{* *}$ & $(3.197)^{* *}$ & & $(2.382)^{*}$ & $(2.554)^{* *}$ \\
Class 1997 & 0.337 & 0.341 & & 0.302 & 0.366 \\
& $(2.271)^{*}$ & $(2.769)^{* *}$ & & $(2.304)^{*}$ & $(3.214)^{* *}$ \\
Class 1998 & 0.268 & 0.353 & & - & - \\
& $(1.938)$ & $(3.05)^{* *}$ & & - & - \\
Distance at application & 0.000 & - & & 0.001 & - \\
& $(0.141)$ & - & & $(8.243)^{* *}$ & - \\
Foreign applicant & - & -0.772 & & - & 0.051 \\
& - & $(-8.579)^{* *}$ & & - & $(0.486)$ \\
Chi-squared & 752.16 & 6.73 & 822.24 & 5.90
\end{tabular}

* Significant at the $5 \%$ level; ** Significant at the $1 \%$ level. 
Table 7. Benefits to state of geographic sorting provided by university

A. Earnings of workers master's degrees*

B. Present value of increased state GDP**

$\begin{array}{ll}25-34 \text { years } & \$ 45,930 \\ 35-44 \text { years } & \$ 68,956 \\ 44-55 \text { years } & \$ 62,744 \\ 55-64 \text { years } & \$ 67,582 \\ & \$ 994,031 \\ & \$ 99,403 \\ & 20.2\end{array}$

C. Present value of increased state tax receipts

D. Increased probability of living in California (percentage points)

* Current Population Survey, 1998, Table P-32; ** At 5\% real interest rate; ** Assumed tax rate of $10 \%$.

The increased probability that alumni will live in California - roughly twenty percentage points - means that state GDP is increased by roughly \$3.75M dollars for each five out-of-state students who are attracted to Berkeley and tax revenues are increased by about $\$ 375,000$. The fiscal benefits to the state from the geographical sorting function provided by the university are quite large.

\section{References}

Aley J (1997) The heart of Silicon Valley. Fortune 136(1), July 7: 66

Cal Business Fall (1997-1999) Haas School of Business, University of California, Berkeley, various issues: Spring 1997, Fall 1997, Spring 1999, Fall 1999

Feder B (1999) 'Stanford start-ups': Provost's revamping of university courses built the regional economy. San Jose Mercury News, December 23

Healy J, Levander M (1998) Lucent establishing presence at Stanford. San Jose Mercury News: $3 c$, July 2

Isard W (1960) Methods of regional science. MIT Press, Cambridge, Massachusetts

Kirby C (1999) Stanford embraces E-commerce curriculum: New research center brings topic to core MBA program. San Francisco Chronicle, December 14

News R (1997) Public affairs office. University of California, Berkeley, April 2

Norr H (1999) Growth of a silicon empire: Bay Area's fertile ground helped sprout high technology industry. San Francisco Chronicle, December 27

Placement R (1992-1999) Chetkovich career center, Haas School of business. University of California, Berkeley, various issues, 1992 through 1999

Saxenian A (1996) Regional advantage: Culture and competition in Silicon Valley and Route 128. Harvard University Press, Cambridge, Massachusetts 